\title{
ANALISIS PENAMPATAN LOKASI STATION AIS (AUTOMATIC IDENTIFICATION \\ SISTEM) DI AMBON GUNA MENDUKUNG MONITORING ALKI (ALUR LAUT KEPULAUAN INDONESIA) III SECARA MAKSIMAL
}

\author{
Jacob D.C. Sihasale ${ }^{1)}$, Jerry R. Leatemia ${ }^{2)}$ \\ e-mail: ${ }^{1)}$ Jacob.sihasale@ fatek.unpatti.ac.id, ${ }^{2}$ yc8vcc@yahoo.com \\ ${ }^{1)}$ Fakultas Teknik Universitas Pattimura - Ambon, ${ }^{2}$ Loka Monitor Ambon
}

\begin{abstract}
ABSTRAK
AIS ( Automatic Identificatioan Sistem) sebuah alat navigasi yang di wajibkan berada dan berfungsi baik di atas kapal dengan kapasitas 300 DWT ke atas, Sesuai dengan Aturan yang di tetapkan oleh IMO.

AIS merupakan sebuah Peralatan Navigasi di atas Kapal yang befungsi meberikan informasi tentang data kapal, posisi serta kecepatan kapal yang di pancarkan menggunakan frekuensi radio VHF.

Data AIS sangat berguna bagi monitoring pergerakan perkapalan di laut dimana lalulintas kapal yang berdapat dilihat dan diamati pergerakannya.Ketersedianya peralatan Penerima signal AIS di darat di Indosesia hanya terdapat pada Instansi, Badan yang berhubungan keamanan pelayaran dan itu tidaktidak semuanya, misalnya dinas perhubungan dan station pantai.Tersedianya Station Penerima Signal AIS di Dunia Pendidikan sangat di butuhkan Guna Perkembangan Pendidikan dan Penelitian bidang pelayaran khususnya mengenai keselamatan pelayaran.

Di Ambon telah tersedia Station Penerima Signal AIS di Kampus Fakultas Teknik Universitas Pattimura yang selain berfungsi untuk monitoring pergerakan kapal di laut Maluku juga untuk mendapatkan data pelayaran guna Penelitian lanjutan dan sarana berbagi informasi kepada masyarakat, dengan jangkauan terjauh $50 \mathrm{Nm}$ dari station.

Ketersediannya Staton Penerima Signal AIS ini akan sangat efektif jika dapat menjangkau luas area yang lebih luas,

Guna dapat menjangkau area yang lebih luas, dalam hal ini daerah ALKI III baik A,B dan C maka di butuhkan sebuah station AIS yang jangkauannya harus dapat menjangkau daerah tersebut.

Untuk menjangkau daerah AKLI III tersebut di butuhkan sebuah penelitan tentang lokasi terbaik di kota Ambon yang dapat menerima signal AIS dari kapal yang berada pada daerah AKLI III tersebut, dengan memperhatikan Karakteristik Frekuensi gelombang Radio VHF dan ketiggian sebuah lokasi dan hal lainnya.
\end{abstract}

Kata Kunci: AIS, Radio, VHF, ALKI

\section{PENDAHULUAN}

Indonesia di bagi Atas 3 Wilayah Alur Laut Kepulauan Indonesia sejak di tetapkannya Peraturan Pemerintah No 37 Tahun 2002. Dengan membagi wilayah Indonesia untuk dilewati oleh 3 jalur ALKI dengan adanya keputsan IMO pada sidang Marine Safety Comitte ke-69. Jalur ALKI menjadi sebuah representasi dari luasnya wilayah perairan yurisdiksi nasional yang berkaitan erat dengan status Indonesia sebagai sebuah negara maritime.

ALKI merupakan wilayah terbuka yang membagi Indonesia atas 4 bagian strategis. ALKI terbentuk setelah United Nations Convention on the Law of the Sea (UNCLOS) tahun 1982 (yang diratifikasi dengan UU No. 17 Tahun 1985) dan dinyatakan sebagai hukum positif internasional sejak 16 November 1994 telah mengakui hak Indonesia sebagai Archipelagic State (Wahyono, 2007), Pengakuan tersebut muncul karena Indonesia memiliki garis pantai sepanjang 81.000 kilometer dan luasnya bentang landas kontinen.

Mengingat persebaran pulau-pulau baik yang berada di wilayah perairan dalam maupun perbatasan Indonesia yang berada pada jalur ALKI I, ALKI II dan ALKI III maka prospek penjagaan keamanan laut wajib ditingkatkan dengan menyesuaikan luas wilayah yang dimiliki. Sedangkan ALKI III yang di bagian selatan bercabang tiga menjadi ALKI III A (sekitar perairan Laut Sawu, Kupang), ALKI III B, ALKI III C (sebelah timur Timor Leste),dimana ALKI III D (sekitar perairan Aru). Keberadaan tiga jalur ALKI tersebut selain merupakan jalur pelayaran internasionaljuga berfungsi sebagai "pintu gerbang memanjang" yang seolah membelah wilayah kelautan Indonesia. Fenomena itu dapat menjadi suatu hal yang menguntungkan, tetapi di sisi lain membawa potensi ancaman terhadap keselamatan pelayaran, pertahanan dan keamanan Indonesia

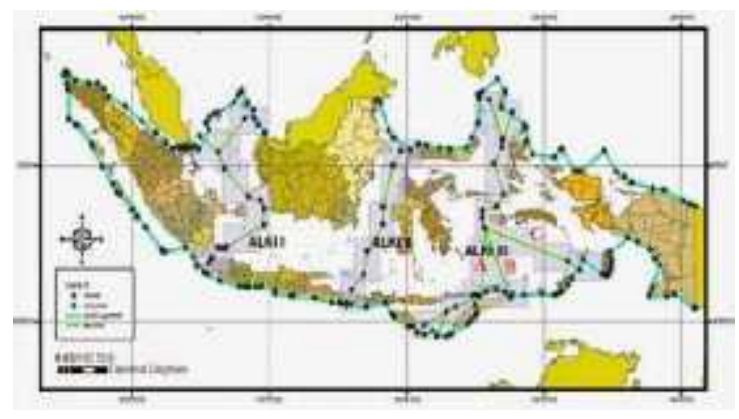

Gambar 1. Peta AKLI Indonesia. 
AIS ditujukan untuk membantu awak kapal dalam bernavigasi dan memungkinkan pihak berwenang maritim untuk melacak dan memantau gerakan kapal, Sistem AIS terintegrasi dari Radio VHF transceiver standar dengan Loran-C atau Global Positioning System ( GPS), dan dengan sensor navigasi elektronik lainnya, seperti gyrocompass dan lain-lain. AIS yang digunakan pada peralatan navigasi penting untuk menghindari dari kecelakaan akibat tabrakan, Penentuan Posisi Kapal, dan Karena keterbatasan dari kemampuan radio, dan karena tidak semua kapal yang dilengkapi dengan AIS, sistem ini diutamakan untuk digunakan sebagai alat peninjau dan untuk menghindarkan resiko dari tabrakan daripada sebagai sistem pencegah tabrakan secara otomatis, sesuai dengan International Regulations for Preventing Collisions at Sea (COLREGS).

Sementara itu, persyaratan AIS hanya untuk menampilkan dasar teks informasi, data yang berlaku dapat diintegrasikan dengan sebuah graphical electronic chart atau sebuah tampilan radar, menyediakan informasi navigasi gabungan pada sebuah tampilan tunggal. AIS juga berfungsi agar dinas Depertemen terkait dapat memonitor akan keberadaan dan olah gerak kapal pada mendekati pelabuhan atau dapat mendeteksi keberadaan kapal yang berada pada daerah jangkauan penerimanan Signal AIS tersebut, dan juga instansi pendidikan dimana data yang di dapat digunakan untuk berbagai penelitian. Begitu pentingnya peran AIS dalam kelangsungan sistim perkapalan sangat dibutuhkan, khususnya dalam mendapakan data operasional sebuah kapal. Data sangat dibutuhkan guna penelitian berbagai hal yang yang berhubungan dengan operasional kapal, kecelakaan kapal, pemakaian behan bakar dan sebagainya.

Berawal dari pemahaman seberapa penting data yang di butuhkan guna sebuah opersiaonal sebuah kapal maka dibutuhkan sebuah stasion penerima AIS di berbagai tempat di Indonesia khususnya bagi pengelola pelayaran, Badan SAR, Badan pertahanan, perusahan pemilik kapal tersebut dan tak kalah penting adalah Lembaga pendidikan yang mempelajari tentang sistim perkapalan maka di buat sebuah penelitian .

Penelitian tersebut di beri Judul: Analisis Penampatan Lokasi Station AIS ( Automatic Identification Sistem) Di Ambon guna mendukung Monitoring ALKI ( Alur Laut Kepulauan Indonesia III Secara maksimal.)

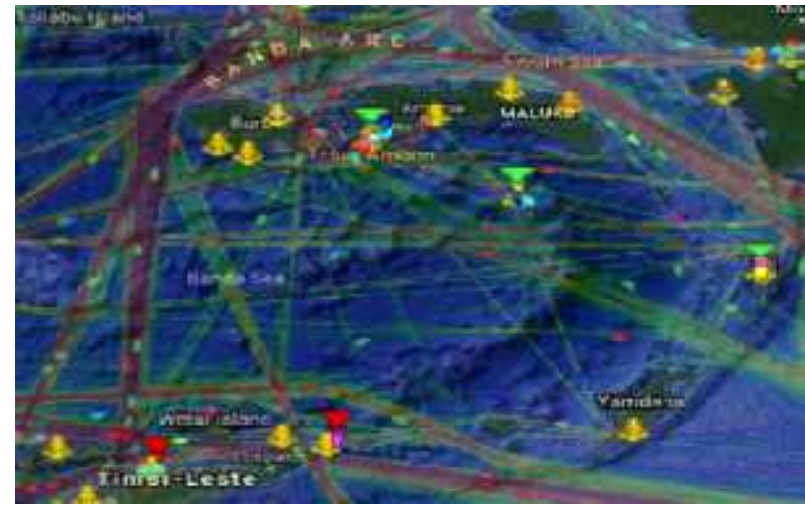

Gambar 2. Pantauan AIS Pulau Ambon by marinetraffic.com

\section{KAJIAN TEORI}

\subsection{Gambaran umum AIS.}

Pada SOLAS Bab V Peraturan 19 memberikan isyarat kepada kita bahwa :

a. semua kapal harus membawa peralatan dan sistim navigasi (Carriage requirements for shipborne navigational systems and equipment)

b. semua peralatan navigasi yang harus ada di atas kapal sesuai dengan tipe kapalnya.

Pada tahun 2000, IMO mengadopsi persyaratan baru bahwa semua kapal harus dilengkapi dengan automatic identification systems (AIS) yang mampu memberikan informasi tentang kapal, ke kapal lain dan pemangku jabatan di suatu Negara pantai, secara otomatis. Peraturan tersebut mewajibkan kapal-kapal $300 \mathrm{GT}$ atau lebih yang berlayar secara internasional (international voyage), kapal-kapal barang 500 GT atau lebih yang berlayar secara internasional dan kapal penumpang tanpa melihat ukurannya, harus dilengkapi dengan AIS. Peraturan tersebut berlaku secara penuh untuk semua kapal, pada tanggal 31 Desember 2004. Transponder AIS menayangkan informasi secara otomatis, seperti posisi, kecepatan, dan status navigasi pada interval waktu tertentu melalui transmitter VHF yang terpasang pada transponder. Informasi tersebut diambil langsung dari sensor navigasi kapal, khusussnya dari penerima GNSS dan gyrocompasnya. Informasi lain, seperi nama kapal dan kode pemanggil VHF di program ketika memasang peralatan juga ditransmisikan secara berkala. Sinyal tersebut diterima oleh transponder AIS yang dipasang pada kapal atau di darat bergantung pada sistemnya, seperti pada sistem VTS. Informasi yang diterima dapat ditampilkan pada sebuah layar atau plot grafik yang menunjukkan posisi kapal lain dengan tampilan sesuai yang terdapat pada layar radar.

Standar AIS menjelaskan 2 kelas unit AIS: 
1. Kelas A, digunakan pada kapal-kapal yang tercantum dalam SOLAS Chapter V (dan kapal lain di beberapa negara)

2. Kelas B, menggunakan daya yang kecil, biaya yang relatif murah untuk penggunaan pasar nonSOLAS.

Varisai-variasi yang lain saat ini sedang dalam pengembangan dan di khususkan untuk penggunaan di stasiun, pertolongan navigasi darurat dan SAR, yang mana peralatan tersebut akan menjadi pengganti dari peralatan sebelumnya. Khusus untuk kelas A, transponder AIS ini terdiri dari sebuah transmitter VHF, 2 penerima VHF TDMA, satu penerima VHF DSC, penghubung menuju displai dan sistim sensor menggunakan komunikasi elektronik berstandar maritim (seperti NMEA 0183, yang dikenal dengan IEC 61162). Pengalokasian waktu menjadi bagian yang sangat vital untuk proses sinkronisasi yang baik dan pemetaan untuk kelas A. Oleh karena itu, setiap unit diharuskan memiliki penerima GPS internal.

Peralatan Ais di darat atau pada base stasiun terdapat peralatan yang paling sederhana terdiri dari 3 opsi yaitu :

Peralatan Ais di darat atau pada base stasiun terdapat peralatan yang paling sederhana terdiri dari 3 opsi yaitu :

\section{Option 1: PC dengan sound card}

- Receiver radio dengan discriminator output 9600 bps paket radio output.

- Audio Kabel antara PC dan radio

- PC dengan Sound Card yang di lengkapi dengan software Shipplotter, yng komplit. AISMon dengan software navigator memiliki SeaClear atau WinGPS.

\section{Option 2: PC with serial port}

- Receiver AIS dengan standar mesin NASA AIS atau SR161/SR162. Yang merupakan mikroprosesor yang dapat mentranslet Signal AIS ke NMEA.

- PC yang siap kerja dengan serial port dan memiliki navigation software dapat memproses bahasa program NMEA Atau AIS

\section{Option 3: Internet}

Dapat langsung berkomunikasi dengan kantor melalui internet dengan yang bertanggung jawab tentang pelayaran kapal atau kita sendiri dapat masuk ke Jaringan Web mereka yang telah memiliki Informasi AIS.

\subsection{Maritime Mobile Service Identity (MMSI)}

MMSI adalah sebuah seri dari 8 digit nomor yang dikirim dalam bentuk data digital melalui sebuah channel frekuensi radio dengan tujuan sebagai identitas khusus (unik) dari sebuah kapal kepada stasiun kapal, stasiun pantai, stasiun bumi, stasiun pantai dan bumi, serta grup pemanggil.

\subsection{Bentuk data yang dikirim AIS}

Data yang AIS yang dikirim dari kapal adalah :

1. Data dinamis

2. Data Statis atau data yang di Input.

Data Dinamis adalah data yang dikirim dari kapal yang selalu berubah tidak tetap, seperti kecepatan kapal dan kedalaman Air laut dll. Data Statis adalah data yang sudah tetap dan di input kedalam sistim AIS seperti data Nama Kapal, Jenis Kapal, Nama Panggilan Kapal dan Nomor Registrasi Kapal dll. Selain Data yang dikirim di Atas Fungsi AIS juga dapat mengirim pesan ke VTS maupun Ke Kapal Lainnya.

\subsection{Prinsip kerja AIS}

AIS bekerja dengan menggunakan frequensi sangat tinggi (Very High Frequency - VHF), yaitu antara 156 - $162 \mathrm{MHz}$. Sistim yang ada secara umum ada 2 jenis, yaitu AIS Class A dan AIS Class B. Namun AIS yang sesuai dengan standard IMO adalah AIS Class A (IMO Resolution A.917(22)), yaitu AIS yg menggunakan skema akses komunikasinya menggunakan sistim SO-TDMA (Self-organized Time Division Multiple Access) sedangkan AIS Class B menggunakan sistim CS-TDMA (Carrier-sense Time Division Multiple Access). Daya pancaran AIS Class A sampai dengan 12,5 watt sedangkan AIS Class B hanya 2 watt, dan fasilitas lainnya yang dimiliki oleh AIS Class A lebih lengkap dbanding dengan AIS Class B

\section{Perbedaan AIS Klas A dan Klas B .}

Perbedaan antara ais Kelas A dan AIS kelas B adalah:

- Class A dapat menyampaikan laporan setiap 10 detik sedangkan Class B setiap 30 detik;

- Class A mampu mengirimkan IMO number, sedangkan Class B tidak;

- Class A dapat mengirim ETA atau tujuan kapal, sedangkan Class B tidak;

- Class A dapat mengirimkan status navigasi, sedangkan Class B tidak;

- Class B hanya disyaratkan dapat menerima pesan keselamatan tertulis, sedangkan Class A harus dapat mengirim dan menerima;

- Class B hanya disyaratkan dapat menerima pesanpesan biner, sedangkan Class A harus dapat mengirim dan menerima;

- Class B tidak perlu dapat mengirim informasi Rate of turn kapal, sedangkan Class A harus dapat. 
- Class B tidak disyaratkan dapat mengirim sarat kapal (maximum present static draught), Class A harus dapat.

- Class A Memancar hanya 12,5 Watt, sedangkan Class B memencar hanya 2 Watt.

\subsection{Bagian Utama Stasiun Penerima AIS.}

Bagian Utama Penerima AIS adalah :

1. Antena

2. Radio Penerima

3. PC yang telah terinstal dengan Software AIS

Antena yang digunakan haruslah menggunakan Antena dengan penguatan besar agar dapat menerima signal AIS dari kapal yang cukup jauh. Selain Antena yang digunakan harus mempunyai penguatan penerimaan yang besar tetapi bentuk dan letak dari antena tersebut juga berpengaruh pada besarnya luas daerah penerimaan signal AIS dari kapal. transponder AIS menggunakan dua frekuensi yang berbeda, maritim saluran VHF 87B $(161,975 \mathrm{MHz})$ dan 88B $(162,025 \mathrm{MHz})$, dan menggunakan 9,6 kbit / s Gaussian minimum shift keying (GMSK) modulasi melalui saluran $\mathrm{kHz} 25$ atau 12,5 menggunakan Data Link Control tingkat tinggi (HDLC)

\section{METODE PENELITIAN}

\subsection{Metode}

Metode yang di gunakan dalam penelitan ini adalah :

a. Metode Literatur

b. Metode pengukuran Langsung

\subsection{Lokasi Penelitian}

Lokasi Penalitian pada 3 Lokasi di Di Pulau Ambon, yaitu:

1. Gunung Nona Dusun Kramat Jaya.

2. Desa Seri Atas.

3. Karang Panjang Atas.

\subsection{Waktu dan Tempat Penelitian.}

Waktu penelitian dilakukan pada saat di luar jam kerjaya itu diatas Jam 17:00 Wit hingga selesai. Ini di maksudkan agar tidak memnggagu waktu kerja ketua peneliti dan anggota peneliti.

Penelitian di lakukan di 3 lokasi berbeda yang secara geografis mempunyai ketinggian di atas permukaan laut berbeda.

Lamanya penggambilan data hanya setiap 3 menit, mengingat data yang terkumpul sangat banyak dan kepasitas penyimpanan data pada laptop terbatas .

\subsection{Peralatan yang Digunakan}

Dalam Penelitian ini Peralatan yang di gunakan adalah sebagai berikut:

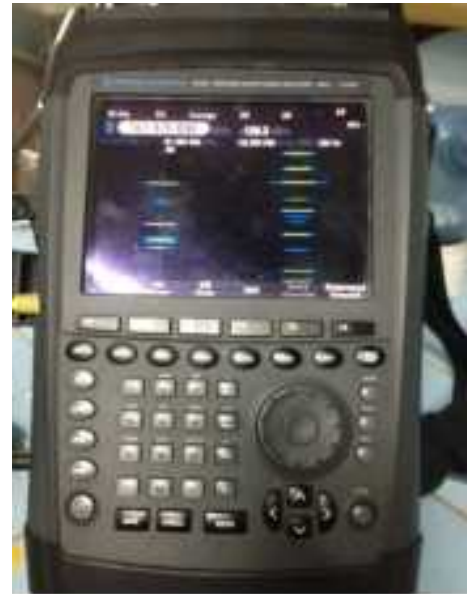

Gambar 3. Spectrum Analaiser Rohde \& Schwarz, Type PR 100.

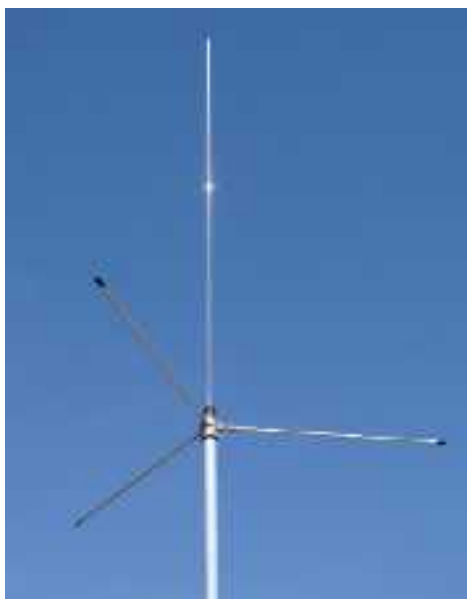

Gambar 4. Antena Penerima Signal AIS

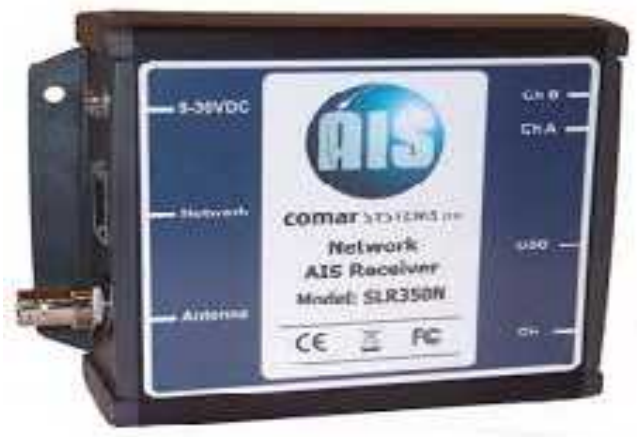

Gambar 5. Radio Penerima Signal AIS

\section{HASIL DAN PEMBAHASAN}

\subsection{Hasil Monitoring dan Analisa}

Hasil Monitoring Lokasi Karpan. 5 Desember 2017, Hasil Monitoring di lokasi Karang panjang dengan Koordinat 3.688744 S dan 28.190599 E dengan menggunakan alat ukur spectrum dan shipploter didapat hasil sebagai berikut : 


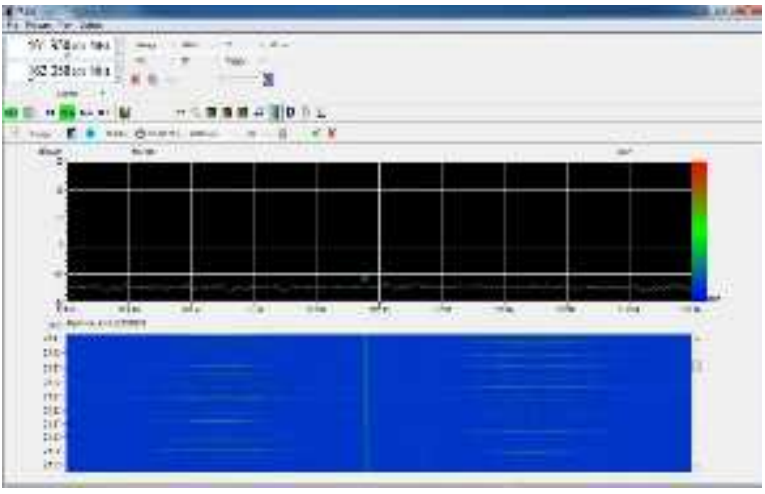

Gambar 6. Monitoring Spectrum AIS CH 87 dan CH 88

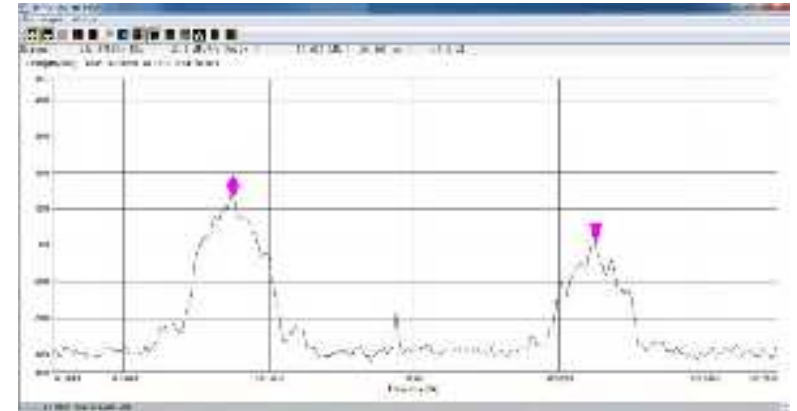

Gambar 7. Monitoring Spectrum AIS CH 87 dan CH 882 Dimensi

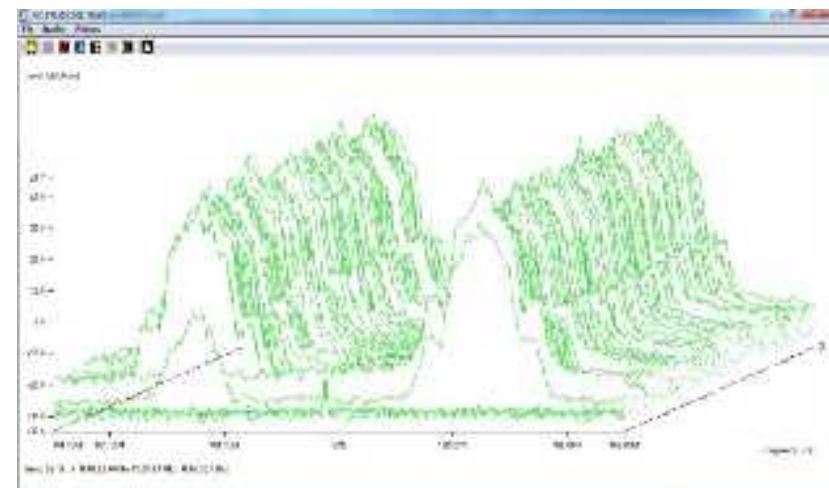

Gambar 8. Monitoring Spectrum AIS CH 87 dan CH 88, 3 Dimensi

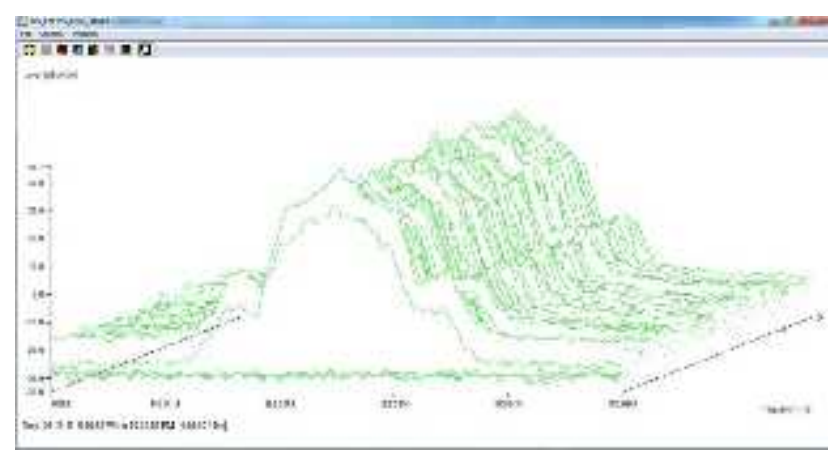

Gambar 9. Spektrum CH 88, 3 Dimensi

Hasil Monitoring Lokasi Dusun Kramat Jaya Gg. Nona

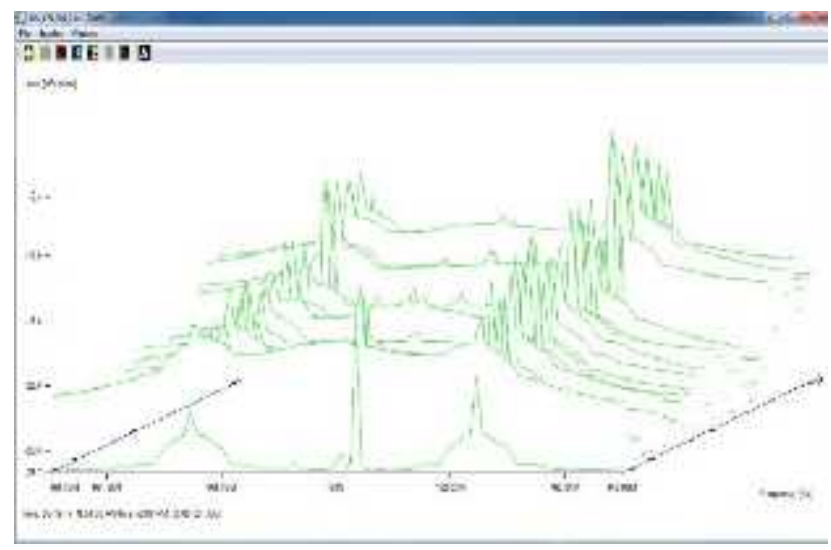

Gambar 10. Spektrum CH 87 dan 88, 3 Dimensi

\section{Hasil Monitoring Lokasi Desa Seri}

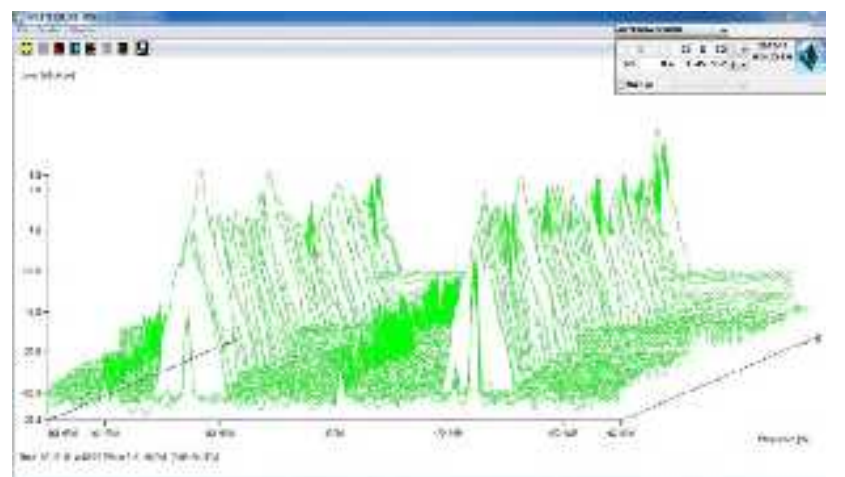

Gambar 11. Spectrum AIS CH 87 dan $\mathrm{CH} 88,3$ Dimensi

\subsection{Hasil Analisa.}

Dari ketiga lokasi tersebut, Data Pengukuran dari Spektrum Analayser dan data Shipplotter kemudian di lihat kesesuaiannya, kemudian dengan menggunakan mikrosoft excel diolah hingga mendapatkan Jarak terjauh pada saat itu. Hasil analisa dapat di lihat di salah satu table berikut :

Tabel 2. Hasil Analisa Level dan Jarak

\begin{tabular}{|c|c|c|c|c|r|}
\hline NO & Frekuensi & Jam & Level & MMSI & JARAK \\
\hline 1 & 161,975 & $21: 03: 50$ & 14.44 & 525023162 & $\mathbf{1 2 . 3 7}$ \\
\hline 2 & 162,025 & $21: 03: 52$ & 20.64 & 525119048 & $\mathbf{9 . 3 2}$ \\
\hline 3 & 162,025 & $21: 03: 55$ & 9.74 & 525019401 & $\mathbf{1 2 . 2 5}$ \\
\hline 4 & 162,025 & $21: 03: 55$ & 8.34 & 525005379 & $\mathbf{1 2 . 6 7}$ \\
\hline 5 & 161,975 & $21: 03: 56$ & 20.64 & 525014072 & $\mathbf{1 3 . 3 4}$ \\
\hline 6 & 161,975 & $21: 03: 56$ & 3.84 & 525005339 & $\mathbf{7 . 7 8}$ \\
\hline 7 & 162,025 & $21: 03: 57$ & 18.14 & 525014013 & $\mathbf{5 1 . 0 5}$ \\
\hline 8 & 161,975 & $21: 03: 58$ & 15.64 & 525101056 & $\mathbf{7 . 1 2}$ \\
\hline 9 & 161,975 & $21: 04: 02$ & 20.34 & 525001150 & $\mathbf{1 9 . 9 5}$ \\
\hline 10 & 161,975 & $21: 04: 02$ & 13.64 & 525119048 & $\mathbf{9 . 3 1}$ \\
\hline
\end{tabular}




\begin{tabular}{|c|c|c|c|c|c|}
\hline 11 & 162,025 & 21:04:08 & 17.54 & 525014013 & 51.05 \\
\hline 12 & 162,025 & 21:04:08 & 8.94 & 525007400 & 25.31 \\
\hline 13 & 161,975 & $21: 04: 10$ & 11.64 & 525020372 & 13.38 \\
\hline 14 & 161,975 & 21:04:41 & 9.94 & 525001150 & 19.95 \\
\hline 15 & 162,025 & 21:04:41 & 8.14 & 525023162 & 12.37 \\
\hline 16 & 162,025 & $21: 07: 13$ & 28.04 & 525020372 & 13.38 \\
\hline 17 & 162,025 & 21:07:29 & 1.54 & 525015645 & 48.71 \\
\hline 18 & 162,025 & 21:09:15 & 34.34 & 525019401 & 12.25 \\
\hline 19 & 161,975 & $21: 13: 57$ & 31.04 & 525101056 & 7.12 \\
\hline 20 & 162,025 & $21: 16: 48$ & 16.54 & 525015645 & 48.71 \\
\hline 21 & 161,975 & $21: 20: 42$ & 23.84 & 525001049 & 7.11 \\
\hline 22 & 162,025 & $21: 21: 15$ & 33.14 & 525019401 & 12.22 \\
\hline 23 & 161,975 & $21: 21: 21$ & 13.64 & 525001150 & 19.95 \\
\hline 24 & 162,025 & $21: 23: 11$ & 20.74 & 525001049 & 7.12 \\
\hline 25 & 162,025 & $21: 23: 52$ & 33.74 & 567451000 & 12.53 \\
\hline 26 & 161,975 & $21: 26: 50$ & 20.14 & 525015645 & 48.72 \\
\hline 27 & 162,025 & 21:28:09 & 6.44 & 525020372 & 13.37 \\
\hline 28 & 161,975 & $21: 30: 21$ & 20.04 & 525001150 & 19.95 \\
\hline 29 & 161,975 & $21: 37: 11$ & 25.74 & 525023162 & 12.34 \\
\hline 30 & 161,975 & $21: 37: 57$ & 32.24 & 525101056 & 7.12 \\
\hline 31 & 161,975 & $21: 40: 24$ & 11.74 & 525019401 & 12.19 \\
\hline 32 & 162,025 & $21: 41: 35$ & 8.74 & 525005379 & 12.71 \\
\hline 33 & 162,025 & $21: 42: 40$ & 13.74 & 525001049 & 7.11 \\
\hline 34 & 162,025 & $21: 43: 57$ & 32.34 & 525007400 & 19.40 \\
\hline 35 & 161,975 & $21: 44: 50$ & 25.74 & 525023162 & 12.32 \\
\hline 36 & 162,025 & 21:48:04 & 34.64 & 525024242 & 113.60 \\
\hline 37 & 161,975 & $21: 48: 16$ & 19.34 & 636016955 & 51.11 \\
\hline 38 & 161,975 & $21: 49: 10$ & 7.64 & 525020372 & 13.39 \\
\hline 39 & 161,975 & $21: 49: 50$ & 11.74 & 525023162 & 12.36 \\
\hline 40 & 162,025 & $21: 50: 52$ & 27.54 & 525001150 & 19.95 \\
\hline
\end{tabular}

\section{KESIMPULAN}

\section{Kesimpulan.}

Dari Hasil servei, Monitoring dan Analisa data Hasil Monitoring selama 30 Menit pada masing masing lokasi dapat di simpulkan bahwa :

1 Pada ketiga lokasi yang berbeda dengan waktu monitoring yang sama di dapatkan Jumlah data yang berbeda dan signifikant, dimana data terbanyak di dapat pada lokasi Dusun Kramat

jaya, Gunung nona itu berarti makin banyak kapal yang Dicover.

2. Pada waktu yang bersamaan dapat terjadi Penerimaan Signal AIS dari beberapa Kapal Secara bersamaan pada chanal yang berbeda.

3. Besarnya atau kecilnya Level penerimaan Signal AIS pada station Penerima bukan berarti Jarak Antara station Penerima dan kapal tersebut Jauh atau Dekat.

4. Lokasi yang paling maksimal untuk mendapatkan data AIS dari pelayaran kapal di seputaran Pulau Ambon dan sekitarnya adalah Lokasi Dusun Keramat jaya Gg Nona Ambon dengan mencapai lebih dari $50 \mathrm{~nm}$ pada kondisi Normal, dan akan lebih jauh pada kondisi tertentu.

5. Pada ketiga Lokasi pengambilan sampel penelitian terdapat gangguan pada frekuensi AIS ( Automatic Identification Sistim ).

6. Gangguan terbesar terjadi pada lokasi Dusun Keramat jaya Gg Nona Ambon ini di sebabkan banyak Ripiter terletak di daerah tersebut yang bekerja pada rekuensi VHF.

7. Pada Dusun Kramat jaya dan Desa Seri tidak terdapat Signal Internet yang Reperentatif guna penyebaran Data AIS.

\section{Saran.}

Guna mendapatkan Data AIS dengan cover area yang lebih luas di harapkan dapat menggunakan lokasi Dusun Kramat Jaya akan tetapi dengan menggunakan fileter pada sistim radio penerima agar terhindar dari gangguan RF Ripiter setempat, serta sedapat mungkin di bangun sistim layanan internet.

\section{DAFTAR PUSTAKA}

1. Afira Genubhy, Pengukuran Karateristik Propagasii Kanal VHF pada Band Orbcomm, Bidang Studi Telekomunikasi Multimedia, Jurusan Teknik Elektro FTI, ITS

2. Ahmad Zatnika Purwalaksana, 2015 otomatisasi transfer data pengamatan automatic weather station (aws) serta pemanfaatannya dalam satellite disaster early warning system (sadewa)

3. Australian Government - Bureau of Meteorology, "Automatic weather stations for agricultural and other applications", (1995) (Updated 2005).

4. Automatic Weather Stations Project. Antarctic Automatic Weather Stations Project. Retrieved on 2008-06-11.

5. ARLL HAND BOOK 2014, The National Association for Amateur Radio.

6. C. Liu, H. Lee, J. Yang, J. Huang, Y. Fang, B. Lee and C. King, "Development of a long-lived, real- 
time automatic weather station based on WSN", In 9. D.Bambang Setiono Adi , Noutika kapal Proceedings of SenSys 2008, (2008), pp. 401-402. penangkap ikan.

7. CUACA DAN IKLIM, Flona W dan Frncis W.

8. da Costa, Jose S, P., Sarmento, A., Gardner, F.

10. Dandan Hendayana,SP, Mengenal Nama dan "Modeling of an ocean waves power device AWS" Proceedings of 2003 IEEE Conference on Control Applications, Vol.1, PP. 618-603, 23-25 Fungsi Alat-alat Pemantau Cuaca dan Iklim,

June, 2013.

11. Electrical and Electronics Engineering: An International Journal (ELELIJ) Vol 2, No 4, November 2013 